\title{
The Effect of Organizational Culture, Interpersonal Communication, Work Motivation to Teacher's Performance
}

\author{
A.Kadir ${ }^{1}$, Bibin Rubini ${ }^{2}$, Thamrin Abdullah ${ }^{3}$ \\ Post Graduate Program, Universitas Pakuan Bogor, Indonesia \\ Iakadir@gmail.com, ${ }^{2}$ bibin.unpak@yahoo.com, ${ }^{3}$ thamrin.unpak@yahoo.com
}

\begin{abstract}
The aim of this study is to examine the influence of Organizational Culture, Interpersonal Communication, Work Motivation to Teacher's Performance either individually or jointly. Variables of Organizational Culture, Interpersonal Communication, Work Motivation as independent variables while the dependent variable is Teacher's Performance. The study was conducted on randomly selected 160 teachers of Senior Islamic High School in the city of Jambi, Indonesia. Using mix method, a sequential explanatory design is applied where quantitative come first. The study both quantitatively and qualitatively reveals that there is a positive significant relationship between variables under the following distribution of coefficient of correlation: Organizational Culture to Teacher's Performance $=0.646$, Interpersonal Communication to Teacher's Performance $=0.681$, Work Motivation to Teacher's Performance $=0.660$ and when tested together it produces coefficient of correlation $=0.613$ and coefficient of determination $=0.375$ indicating the existence of other $62.5 \%$ variables not including in the model affecting performance within the teachers' working environment.
\end{abstract}

Keywords: Organizational Culture, Interpersonal Communication, Work Motivation, Performance.

\section{INTRODUCTION}

Teachers as educators is a decisive educational leader in the learning process during classroom interaction where leadership roles will be reflected in how teachers carry out the role and tasks. This means that the performance of teachers is the crucial factor for the quality of learning that will have implications on the quality of educational output after students have completed their education at the school.

This study attempts to examine the phenomenon that occurs in teachers as a teacher and educator as in general there is a tendency of teachers considering teaching only as a routine activity without any further innovational development, becoming less motivated to excel, just as the teachers in charge of teaching making other educational aspects such as conducting guidance or enrichment to students received less attention.

Preliminary observations of the teachers in Madrasah Aliyah (Islamic Junior High School) in the district of Batang Hari Jambi Province, Indonesia which is the subject of this study generated the following information (a) the percentage of teachers who have not been able to create a syllabus and lesson plans in accordance with the standardized process reached 58\%; (b) the percentage of teachers who have not been able to carry out varied learning methods according to the characteristics of subjects reached $50 \%$; (c) teachers who have not been able to devise means of evaluation of learning outcomes in accordance with the indicator reached 65\%; (d) the percentage of teachers who have not been able to analyze the results of the evaluation of learning and to develop as well as to implement a program reached $65 \%$; and (e) the percentage of teachers who do not carry out the administration of the learning program reached $80 \%$.

Realizing the importance of organizational culture, interpersonal communication, work motivation to teacher's performance, then the problem in research is formulated as follows:

1. Does organizational culture positively affect Islamic junior high school teacher's performance?

2. Does interpersonal communication positively affect Islamic junior high school teacher's performance?

3. Does work motivation positively affect Islamic junior high school teacher's performance?

4. Do organizational culture, interpersonal communication and work motivation altogether affect Islamic junior high school teacher's performance? 


\section{LITERATURE REVIEW}

The literature will highlight variables affected the performance of the teacher in the area of organizational culture, interpersonal communication, work motivation to teacher's performance together with the dimensions forming these variables.

\subsection{Teacher's Performance}

According to Robinson, et.al (2009), the performance of an individual is the contribution to the achievement of organizational goals. A person's performance will be crucial for the performance of the organization as according to Gibson, et.al (2012) individual performance is the basis for organizational performance. Furthermore, they described that performance is closely related to the behavior of an individual and is influenced by various factors such as (a) the individual variables, consisting of abilities and skills, the background of a person's life including family, experience and social class; (b) psychological variables, consisting of: motivation, attitude, Interpersonal Communication, perception and learning; (c) organizational variables, consisting of: leadership, organizational resources, organizational structure, and so on.

According to Griffin (2008), performance is determined by three main issues: capabilities, needs, and an environment. Without knowing these three factors, a good performance will not be achieved. It is understandable that people who have a good performance, will know how to do the job properly, have a high desire to do it, and to know the whole main factors that affect their work. Since the behavior of individuals is determined by the combined efforts of the working people and the environment, each individual can make a decision on his behavior in the organization, so that every individual has differences in terms of needs, desires, and goals

Based on the above description, it can be concluded that teacher performance is the contribution of teachers to the achievement of organizational goals that can be seen in the behavior through the performance of teachers in carrying out the tasks assigned to them. The result will be reflected in the output, both the quantity and quality which is characterized by indicators: (a) the planning of learning programs; (b) the implementation of learning programs; (c) evaluation of learning; (d) following up the results of the evaluation.

\subsection{Organizational Culture}

According to Robbins, Judge, and Boyle (2013), organizational culture is a value system that was developed in an organization that distinguishes these organizations and other organizations. Schein (2012) defines organizational culture or the culture of a group as the basic assumptions learned by a group to solve the problems of external adaptation and internal integration which works quite well and valid. Therefore, the organizational culture is taught to new members as the correct way to feel, think, and feel a connection with the problems.

Further, Schein provides some general understanding of the organizational culture as follows: (a) the regularity of the observed approach when interacting with others; (b) the norms that develop within the group; (c) the dominant values supported by the organization; (d) the philosophy that directs the policies of the organization; (e) the rules of the game that should be followed and accepted by members of the organization; (f) the climate in an organization; (g) the specific competencies of the group shown in completing bounded; (h) the habit of thinking, mental models, and patterns of the language used by members of the group; (i) the emergence of mutual understanding built among group members; and (j) the ideas, feelings, and impressions of the group that built characteristics of themselves as a group.

Based on the above it can be concluded that organizational culture is a way of viewing and basic assumptions underlying values, norms, and beliefs of individuals within the organization and are formed from the interaction between members of the organization to achieve common goals. The indicators: (a) complying with the norms; (b) the values that are believed; (c) trust in the organization; (d) coherence with other members of the organization; (e) a clear roadmap; and (f) the seriousness to the achievement of working together in the organization.

\subsection{Interpersonal Communication}

Gibson, et.al (2012)) argues interpersonal communication is the main way in daily managerial communication as usually more than a quarter of managerial communication occurs face to face with the following indicators: a) transparency, b) honesty, c) feedback. Schermerhorn (2004) stated that it 
would be useful to look at human communication as a process to send and receive symbols containing a message from one person to another. The basic process between people is the basis for the discussion of issues of greater communication within an organization and there are three factors in interpersonal communication to foster good interpersonal relationships: a) believe (trust), b) supportive attitude (supportiveness), c) an open attitude (open-mindedness).

McShane and Glinov (2012) concluded that effective interpersonal communication depends on the ability of the sender to get messages from others and receiver performance as an active listener. The indicators are: a) empathy, a person's ability to understand, sensitive to the feelings, thoughts, and situations of others, b) repeating the message: repeating key points several times, c) using time effectively: the message that compete with another message, d) noise, so that the recipient is not disturbed by anything else, and descriptive, focusing on the problem, not the person. Based on the above description, it can be synthesized that interpersonal communications are the delivery and reception of messages in the exchange of information between individuals, directly as well as generating feedback so that the message can be understood by the two parties. The indicators are a) the transmission of information, b) sensitive to the feelings of others, c) feedback, d) information acceptance e) using time effectively, f) comfortable conditions when obtaining information.

\subsection{Work Motivation}

Gibson, et. al (2012) stated that the motivation is characterized with (a) direct from behavior, (b) the strength of the response once an employee chooses to follow the action, and (c) persistence behavior. Furthermore Colquitt, Lepine, and Wesson. (2009), define motivation as a set of energy forces originating both inside and outside employees, determine the direction, intensity, and persistence. Various theories emphasized that there are three elements of motivation, (a) attempts; (B) the organization's goals; (C) requirement. This element is a measure of the intensity of the effort, in this case, if a person is motivated to do his job he will not bend over backward so that high effort will produce outcomes. Thus, work motivation means a push of a person's desire to carry out actions or activities within the scope of the tasks of the job / position within an organization.

From the above description, it can be concluded that, work motivation is the force that drives, moves, and directs both from within and from outside the individual to carry out work in order to achieve the stated goals of both individuals and organizations, which is characterized by the indicators of (a) responsibilities; (b) self-development; (c) independence; (d) the relationship among members; (E) wages earned; $(\mathrm{F})$ the attention of the employer; and $(\mathrm{g})$ meeting the needs of the workplace.

With particular reference to above theories, the following hypothesis is formulated:

1. Organizational culture is positively related to Islamic junior high school teacher's performance.

2. Interpersonal communication is positively related to Islamic junior high school teacher's performance.

3. Work motivation is positively related to Islamic junior high school teacher's performance.

4. Organizational culture, interpersonal communication and work motivation altogether are positively related to Islamic junior high school teacher's performance.

\section{Data Collection}

This study applies mix method with direct observation to the field aimed at analyzing the phenomenon occur when the research took place then confirm the finding by using direct depth interview. This way, writers apply Sequential Explanatory Mixed Methods. Descriptive statistics and quantitative analysis are used for finding an initial solution to the problem encountered. The sample of this study were 160 Islamic high school teachers located in 12 (twelve) Islamic junior highs in Jambi, Indonesia.

Techniques of data collection in this study are in the form of a questionnaire. The normality assumption is prerequisites to proceed to further test. The analysis is conducted with multiple linear regression and hypothesis testing is performed at a significance level of 0.05 .

Depth interview with vice headmaster was performed to confirm the result of quantitative findings. The implication of the research findings is then discussed. 


\section{RESUlT AND DISCUSSION}

The teachers of listed organizations were asked to participate in the survey by responding their opinions for four different measures in Organizational Culture, Interpersonal Communication, Work Motivation, and Performance. The normality is performed with Lilliefors test. Data are normally distributed as the value of each variable is not exceeding the critical value for Lilliefors test. The Lilliefors normality test values for Organizational Culture, Interpersonal Communication, Work Motivation and Performance are $0.067,0.046$ and 0.060 respectively below the critical value of 0.093 for $\mathrm{n}=160$ which is 0.070 .

\subsection{The Effect of Organizational Culture on Performance}

Hypothesis testing confirms that organizational culture positively affects performance with correlation coefficient value of 0.646 and the coefficient of determination $=0.417$. This means that $41.7 \%$ of teacher's performance is determined by organizational culture while the other $48.3 \%$ is contributed by other variables. Similarly, the result of qualitative research interviews, observation, and documentation in twelve Islamic Junior High School in the city of Jambi, confirms the tendency of the relationship between organizational cultures with teacher's performance. This finding strengthens the quantitative research hypothesis results testing that there is a positive significant relationship between organizational culture and teacher's performance.

This is in line with the theory put forward by Colquitt, Lepine and Wesson (2009) that organizational culture is a social knowledge in the organization about the rules, norms, and values that shape attitudes and behavior of employees, so the teacher as a member of the organization must have the ability for to obey and execute all the rules of the organization in order to produce something that is in line with expectations. Organizational culture can be developed by a teacher to create interpersonal communication and commitment of its citizens to fully realize the benefit educational purposes. An organizational culture has a great function in the process of education in Islamic high schools. A teacher who has a high concern for organizational culture will also increase his/her function in carrying out duties in an organization where he/she works. With good organizational culture, teachers are expected to be able to develop their competence, comply with the norms and discipline in carrying out duties, be able to contribute to improving teachers' performance.

\subsection{The Effect of Interpersonal Communication to Performance}

Hypothesis testing confirms that interpersonal communication affects performance with the correlation coefficient value of 0.681 and coefficient of determination $=0.463$. This means that $46.3 \%$ of performance is determined by interpersonal communication while the other $53.7 \%$ is contributed by other variables. Similarly, the result of qualitative research interviews, observation, and documentation in twelve Islamic Junior High School in the city of Jambi, confirms the tendency of the relationship between interpersonal communications to performance. This finding strengthens the quantitative research hypothesis results testing that there is a positive significant relationship between interpersonal communication and performance.

This finding is consistent with the theory put forward by Schermerhorn, (2004) stating that interpersonal communication is communication between people as the process of sending and receiving symbol containing a message from a person to another and how one feels about his work as a whole as well as on various aspects of his job. Interpersonal communication is the emotional state of a teacher in the context of the scope of work that can encourage and motivate teachers to work. Therefore, a teacher who has good interpersonal communication will also improve the performance to be optimized for performing their duties. Furthermore, interpersonal communication in the organization of the school is an important thing to do among people in schools to improve the relationship between the personal and the smooth process of communication, so that the work in the school organization can run smoothly as expected in avoiding the absence of conflict and obstacles. Interpersonal communication will lead to closeness, attachment making people will be able to cooperate and to solve the problem amicably, encourage and motivate teachers to work, in turn, will improve teacher performance.

\subsection{The Effect of Work Motivation to Performance}

Hypothesis testing confirms that work motivation positively affects performance with the coefficient of correlation $=0.660$ and coefficient of determination $=0.435$. This means that $43.5 \%$ of 
performance is determined by work motivation variable while the other $56.5 \%$ is contributed by other variables. Similarly, the result of qualitative research interviews, observation, and documentation in twelve Islamic Junior High School in the city of Jambi, confirms the tendency of the relationship between work motivations to performance. This finding strengthens the quantitative research hypothesis results testing that there is a positive significant relationship between work motivation and performance.

The findings obtained in this study indicate that work motivation is the driving force, mobilizing and directing both from within and from outside the individual to act and behave in achieving the stated goals of the organization.

This is consistent with the theory put forward by Colquitt, Lepine and Wesson (2009) defining motivation as a set of energy forces originating both inside and outside employees to determine the direction, intensity, and persistence.

Islamic junior high school teachers as members of the organization must have a high motivation to give impetus in progressing the organization. Work motivation is one factor that can be improved so that teachers can optimize their function in carrying out their duties to achieve the best education. Thereby, increasing work motivation of teachers will increase teacher's performance in the respective schools.

In performing duty, one is not forever just influenced by extrinsic rewards such as financial compliance alone, but intrinsic motivation is something that cannot be ignored. This includes being pride to himself because he can do a job that others may not be able to do so that can become a driving force to contribute to improving teacher performance.

\subsection{Interaction of Organizational Culture, Interpersonal Communication and Work Motivation to Performance}

When tested together, hypothesis testing results show that there is a significant relationship be-tween organizational culture, interpersonal communication and work motivation to performance. The regression equation generated is $\hat{Y}=19.51+0.242 \mathrm{X} 1+0.455 \mathrm{X} 2+0.152 \mathrm{X} 3$ with correlation of coefficient values $=0.613$ and the coefficient of determination $=0.375$. This means that $37.5 \%$ of performance is caused by variables of organizational culture, interpersonal communication and work motivation while $62.5 .8 \%$ is contributed by other variables not included in the model. The result of qualitative research interviews, observation, and documentation in twelve Islamic Junior High School in the city of Jambi, confirms the relationship among organizational culture, interpersonal communication and work motivation to performance. This finding strengthens the quantitative research hypothesis results testing that there is a positive significant relationship among those mentioned variables.

The findings obtained in this study indicate that, if teachers in performing their duties and functions are able to develop competence in terms of being able to move the organization toward better direction and teachers have felt comfortable in carrying out their duties because all their needs are fulfilled, as well as teachers are able to develop ability to communicate and interact well, then the teachers' performance will increase as well. Thus, a teacher who adheres to organizational culture, possess high interpersonal communication, supported by good work motivation, the teacher will become a good performer.

\section{Conclusion}

The findings reveal that there is a positive and significant direct effect on the organizational culture, interpersonal communication and work motivation to performance.

Based on the initial design of the constellation between variables, the results showed that the contribution of organizational culture to performance is $0.417 \%$, interpersonal communication is $0.463 \%$, and work motivation is $0.435 \%$ indicating the highest individual contribution to the teachers' performance is interpersonal communication. When combined together, a contribution of the three variables of organizational culture, interpersonal communication, and work motivation reaches $37.5 \%$ indicating the contribution of other variables not included in the model to predict performance 
are $62.5 \%$ indicating this model is not of good-fit. Therefore, other researchers wishing to conduct similar studies may include other variables such as; teacher professionalism, achievement motivation, work culture of teachers, teachers' resilience, creativity, work experience, training, principal's management, decision-making techniques and so forth.

\section{REFERENCES}

Colquitt, J., Lepine, J. A., \& Wesson, M. J., Organizational behavior: Improving performance and commitment in the workplace. McGraw-Hill/Irwin, 2009, ch.2 pp. 66-70

Gibson, J. L., Ivancevich, J. M., \& Donnelly, J. H. Konopaske . Organizations: Behavior, structure, processes, 14 (2012).

Griffin, R. W. (2008). Principles of management. Recording for the Blind \& Dyslexic.

McShane, S., \& Von Glinow, M. (2012). Organizational behavior. McGraw-Hill Higher Education.

Robbins, S., Judge, T. A., Millett, B., \& Boyle, M. (2013). Organizational behavior. Pearson Higher Education AU.

Robinson, L., Brittain, K., Lindsay, S., Jackson, D., \& Olivier, P. (2009). Keeping in Touch Everyday (KITE) project: developing assistive technologies with people with dementia and their carers to promote independence. International Psychogeriatrics, 21(03), 494-502.

Schein, E. (2012). Corporate culture. Handbook for Strategic HR: Best Practices in Organization Development from the OD Network, 253.

Schermerhorn, J. R., Hunt, J. G., Osborn, R., \& Osborn, R. (2004). Core concepts of organizational behavior (pp. 146-147). Hoboken, NJ: Wiley. 